\title{
Trajetórias escolares em contexto social desfavorável e as reformas educacionais recentes no Brasil
}

\author{
School trajectories in unfavorable social contexts and the recent education \\ reforms in Brazil
}

\author{
Vanessa Gomes de Castro \\ Doutora em Ciências Sociais \\ Instituto Federal do Norte de Minas Gerais - IFNMG. \\ Araçuaí, Minas Gerais - Brasil. \\ vadecastro@hotmail.com \\ Fernando Tavares Júnior \\ Doutor em Sociologia \\ Universidade Federal de Juiz de Fora - UFJF. \\ Juiz de Fora, Minas Gerais - Brasil. \\ ftavares@caed.ufjf.br
}

\begin{abstract}
Resumo: Este trabalho investigou o transcorrer de um conjunto de trajetórias escolares mediante a antecipação da idade de ingresso no ensino fundamental e a ampliação do tempo de permanência nesta etapa de ensino, instituídos respectivamente pelas Leis n. ${ }^{\circ} 11.114 / 2005$ e n. ${ }^{\circ} 11.274 / 2006$. Assim, foram analisadas trajetórias percorridas de 2006 a 2014, as quais integraram a primeira coorte de alunos de uma determinada escola pública municipal, totalmente submetida às referidas leis. Buscou-se examinar o fluxo dos alunos ao longo desta etapa de escolarização básica, considerando que, no horizonte dessas leis, estão a redução das desigualdades educacionais, especialmente aquelas que se manifestam por meio da reprovação escolar. As trajetórias foram acompanhadas através de diários de classe e atas de resultado final. Concluiu-se que, apesar dos estímulos legais, o fluxo das trajetórias escolares, sobretudo percorridas em contexto social desfavorável, demonstrou-se severamente comprometido pelas reprovações.
\end{abstract}

Palavras chave: políticas educacionais; ensino fundamental; trajetórias escolares; fluxo; reprovação escolar.

Abstract: This study analyzed the development of some school trajectories through the early age of entry to elementary school and the expanded length of stay in this level of schooling, both resolutions established respectively by laws number $11.114 / 2005$ and 11.274/2006. Therefore trajectories from 2006 to 2014 were investigated, those belonging to the first cohort of students from a specific municipal public school, in agreement with the laws mentioned above. The aim was to analyze the students' flow throughout this educational stage, considering that these laws envisage the reduction of inequalities in education, particularly those that become visible through school failure. We followed the trajectories using class diaries and final result minutes. The conclusion is that, despite legal incentives, the flow of school trajectories, especially taking into account unfavorable social contexts, is severely affected by failures.

Key-words: educational policies; elementary school; school trajectories; flow; school failure.

\section{Cite como}

\section{(ABNT NBR 6023:2018)}

CASTRO, Vanessa Gomes; JR TAVARES, Fernando. Trajetórias escolares em contexto social desfavorável e as reformas educacionais recentes no Brasil. Dialogia, São Paulo, n. 39, p. 1-21, e20580, set./dez. 2021. Disponível em: https://doi.org/10.5585/39.2021.20580.

American Psychological Association (APA)

Castro, V. G., \& Jr Tavares, F. (2021, set./dez.) Trajetórias escolares em contexto social desfavorável e as reformas educacionais recentes no Brasil. Dialogia, São Paulo, 39, p. 1-21, e20580. https://doi.org/10.5585/39.2021.20580. 


\section{Introdução}

Nas sociedades contemporâneas, apesar de a educação ser proclamada um direito de todos, no que tange ao acesso, permanência e ensino de qualidade como expressões da equalização das oportunidades sociais, a Sociologia tem nos ensinado que a igualdade de oportunidades não se materializou via escolarização, como esperado pelas teorias liberais desde os anos 1960, como a Teoria do Capital Humano e outras, mesmo nas sociedades industrializadas. Sendo observadas tendências de reprodução das desigualdades (JENCKS, 1972; HIRSH, 1977; BOURDIEU; PASSERON, 1982; BOUDON, 1981). Nesse sentido, a Sociologia da Educação tem evidenciado que as oportunidades educacionais são bens sociais escassos, distribuídos desigualmente na sociedade, entre classes sociais, grupos e indivíduos.

Frente a isso, no Brasil, diversas políticas públicas e legislações educacionais, sobretudo, desde o final do século XX e início do século XXI, têm buscado amenizar as desigualdades de oportunidades perante o ensino e promover uma educação de qualidade para todos. No entanto, apesar das medidas oficiais direcionadas a democratizar o acesso à educação escolar, muito ainda precisa ser feito em termos de qualidade e equidade, principalmente ao se considerar os grupos em contexto social e econômico desfavorecido. Além disso, entre a formulação de políticas e legislações educacionais, sua implementação na escola e a digestão dos sujeitos envolvidos (gestores, professores, alunos e família), há um processo complexo. Assim, este trabalho investigou o transcorrer de um conjunto de trajetórias escolares percorridas em contexto social desfavorável, frente à antecipação da idade de ingresso no ensino fundamental e à ampliação do tempo de permanência nesta etapa de ensino, instituídos respectivamente pelas Leis $n^{\circ} 11.114 / 2005$ e $n^{\circ}$ $11.274 / 2006$.

Desse modo, o transcorrer das trajetórias escolares se refere aos percursos dos indivíduos através do sistema de ensino (fluxo), pelo menos, durante o interstício de escolaridade compulsória, isto é, entre o $1^{\circ}$ e o $9^{\circ}$ ano do ensino fundamental. "Contexto social desfavorável" compreende circunstâncias gerais de inserção social que apresentam limites ao acesso a melhores condições de escolarização/socialização, como origem familiar com baixo nível socioeconômico e baixa escolaridade. A literatura sociológica nos ensina que a origem socioeconômica do aluno pode facilitar ou dificultar sua trajetória escolar. Fatores como as características individuais, o background familiar, a estrutura de oportunidades educacionais e a legislação interferem nos destinos escolares dos indivíduos e grupos, assim como na produção e reprodução social das desigualdades perante o ensino. 
Nesse sentido, a investigação de trajetórias escolares é um campo com um enorme potencial para a Sociologia da Educação, o qual vem se ampliando internacionalmente desde os anos 1980, quando as investigações sobre as desigualdades perante o ensino deixaram de se caracterizar, predominantemente, pela abordagem macrossociológica, passando a desvelar os processos microssociológicos inerentes à vida escolar (NOGUEIRA; FORTES, 2004). Assim, são pesquisadas desde as estratégias educacionais das famílias e dos indivíduos para alcançar o sucesso escolar até a fenomenologia e a etnometodologia envolvendo o cotidiano da família, da escola e da sala de aula (FORQUIM, 1995).

Posto isso, as questões norteadoras deste trabalho são: como transcorreu um conjunto de trajetórias escolares mediante a antecipação da idade de ingresso no ensino fundamental e a ampliação do tempo de permanência nesta etapa de ensino? Em outras palavras, como foi o fluxo escolar dos alunos submetidos às Leis no 11.114/2005 e no 11.274/2006? Destaca-se que o Plano Nacional de Educação (2014-2024), instituído pela Lei no 13.005/2014, entre as suas metas, prevê que $95 \%$ dos alunos concluam o ensino fundamental na idade recomendada, com expectativas sobre a melhoria do fluxo escolar e da aprendizagem. Assim, desenvolveu-se uma metodologia específica para a investigação individualizada e longitudinal de trajetórias escolares, através do acompanhamento de um conjunto de aluno entre o $1^{\circ}$ e o $9^{\circ}$ ano do ensino fundamental, em uma determinada escola pública, com base em diários de classe e atas de resultado final.

\section{Trajetórias escolares no contexto das reformas educacionais}

A antecipação da idade de ingresso, assim como a ampliação do tempo de permanência na educação básica, tornou-se uma preocupação em diversos países em desenvolvimento. No Brasil, a legislação educacional, desde a metade do século XX, tem buscado aumentar gradualmente o tempo de permanência das crianças nesta etapa de ensino. Por meio da Lei $n^{\circ} 4.024 / 1961$, por exemplo, foram estabelecidos quatro anos de escolaridade obrigatória. Com o Acordo Punta Del Leste e Santiago, em 1970, foi estendido para seis anos o tempo de ensino obrigatório. A Lei $\mathrm{n}^{\circ}$ 5.692/1971 aumentou a obrigatoriedade para oito anos. A Lei de Diretrizes e Bases da Educação Nacional n 9.394/1996 sinalizou para um ensino obrigatório de nove anos de duração, a se iniciar aos seis anos de idade, o que, por sua vez, tornou-se meta da educação nacional pela Lei $\mathrm{n}^{\circ}$ 10.172/2001, que aprovou o Plano Nacional de Educação (PNE). No ano de 2006, entrou em vigor a Lei $n^{\circ} 11.274$, que instituiu o ensino fundamental de nove anos de duração, com a inclusão das crianças aos seis anos de idade. Os municípios, estados e o Distrito Federal tiveram até 2010 para implantar a nova legislação. No entanto, alguns estados, como Minas Gerais, já haviam 
anteriormente realizado a ampliação em suas redes estaduais. No caso em análise, a escola onde as trajetórias foram investigadas pertence à rede municipal de ensino, implementando a mudança somente em 2006, no contexto da vigência das referidas leis federais.

A ampliação do ensino fundamental para 09 anos visou oferecer maiores oportunidades de aprendizagem no período da escolarização obrigatória e assegurar que, ingressando mais cedo no sistema de ensino, as crianças prossigam nos estudos, alcançando maior nível de escolaridade, sobretudo aquelas das classes populares, sem interrupções ou evasões. Nessa direção, o foco principal das Leis Federais $n^{\circ} 11.114 / 2005$ e $n^{\circ} 11.274 / 2006$ foi a inclusão, cujos maiores beneficiados são as crianças oriundas das classes populares, ou seja, aquelas que se encontram em contexto social e econômico desfavorável, pois as crianças provenientes das classes privilegiadas e favorecidas já estariam incluídas no sistema de escolarização formal. De modo geral, essas legislações educacionais implantadas no Brasil a partir de 2006 constituem um instrumento legítimo para dar a todas as crianças a oportunidade de usufruir o direito de frequentar mais cedo a escola, o direito à aprendizagem e o próprio direito à educação (SAVELI, 2008).

No Brasil, a maior parte das políticas, legislações, decretos, planos, metas e programas voltados para melhoria da qualidade da escola pública brasileira, seja na esfera federal, estadual ou municipal, têm como principal preocupação o combate à reprovação escolar e a promoção da aprendizagem. Isso porque, desde o final dos anos 1980, diversas pesquisas apontam o grave problema da repetência massiva ao longo da educação básica, enquanto mecanismo que reforça a distribuição desigual da educação na sociedade, sendo um dos principais problemas do sistema de ensino do país (FLETCHER; RIBEIRO, 1987; KLEIN; RIBEIRO, 1995). No que tange aos múltiplos fatores que concorrem para a reprovação escolar, vários trabalhos internacionais evidenciam, entre outras coisas, o papel das mudanças legais, ou na estrutura e funcionamento dos sistemas de ensino; as relações entre a reprovação e o destino das trajetórias escolares; além das representações e atitudes de professores, gestores escolares e famílias acerca das probabilidades de sucesso ou fracasso escolar dos indivíduos (HOUSE, 1989; BYRNES, 1989; TOMCHIN; IMPARA, 1992; FOSTER, 1993; FREY, 2005; BONVIN; BLESS; SCHUEPBACH, 2008; HATTIE, 2012).

Diante disso, esta pesquisa chama a atenção para a relação entre os dispositivos legais, como as leis que anteciparam a idade de ingresso e ampliaram o tempo de permanência no ensino fundamental brasileiro, visando à aprendizagem e à aprovação; e o fato de que as expectativas e representações sociais dos professores sobre a aprendizagem e a aprovação, muitas vezes, vão na contramão de propostas de democratização do ensino. Isso porque, no "chão da escola", a 
reprovação ainda é considerada um instrumento aceitável de punição e correção dos alunos. Estudos indicam que a reprovação das trajetórias escolares está nas atitudes dos professores, nas atividades propostas, nas notas e nos conceitos atribuídos aos alunos, nas advertências e na própria organização da sala de aula. É uma produção social, que cumpre papéis sociais e políticos (TAVARES JR.; SIMÃO, 2016). Logo, torna-se muito difícil mudar o cenário de extrema desigualdade entre os percursos escolares no Brasil, somente com políticas e legislações educacionais, sem uma mudança na mentalidade dos sujeitos envolvidos — gestores, professores, alunos, famílias e comunidade escolar.

Conforme sublinhado por Barbosa (2009), as representações partilhadas pelos professores sobre os alunos é o resultado de seu processo de formação, da constituição de sua identidade profissional e da imagem social da escola pública, revelando-se como fator primordial da baixa qualidade da educação pública brasileira no nível básico. Os professores tendem a acreditar que o fracasso escolar depende, sobretudo, das características individuais do aluno e da falta de condição e cooperação de sua família, em muitos casos, eximindo-se da sua parcela de responsabilidade. $\mathrm{Na}$ literatura sociológica, esse fator ficou conhecido como "efeito pigmalião" ou "profecia autorrealizadora", isto é, o direcionamento das trajetórias escolares, para que sejam parecidas com a percepção ou crença do professor em relação às capacidades dos alunos, indicando fortes associações entre aquilo que o professor vê como futuro para o aluno e como suas atitudes em sala de aula conduzem os alunos a esse futuro (BARBOSA, 2009).

Desse modo, entre a formulação de políticas públicas e legislações educacionais e a sua implementação e degustação pela comunidade escolar, existe um distanciamento, no qual a maioria das reformas educacionais leva muito tempo para atingir suas metas, ou simplesmente não consegue atingi-las, dadas as dimensões simbólicas presentes no dia a dia da escola. Tal ambiente também se constitui um espaço social permeado por conflitos, tensões e, em alguma medida, mudanças, envolvendo interações sociais entre alunos, famílias, professores, gestores e afins, bem como suas representações sociais sobre a realidade. No campo da Psicologia Social, Moscovici (2003) argumenta que as representações dão significados às situações sociais, à comunicação e às condutas dos indivíduos envolvidos. No caso da reprovação escolar, é uma sentença em que, muitas vezes, as representações sociais sustentadas pelos professores em relação aos destinos dos alunos conforme suas origens sociais têm maior peso no veredito final do que suas capacidades cognitivas propriamente ditas.

Assim, a reprovação escolar, por vezes, não é o resultado apenas de evidências objetivas sobre a aprendizagem dos alunos, mas de crenças e representações sociais que os professores fazem 
a respeito dos indivíduos, conforme a classe social, gênero, cor, idade, religião, etc. (BARBOSA 2009). Como bem observado por Lima e Campos (2015), para Moscovici, as crenças e representações sociais estruturam nossas experiências cotidianas, filtrando cognitivamente as informações, de modo a dar sentido à realidade social. Diante disso, uma representação social funciona como um conjunto organizado de convicções e conhecimentos que guiam a comunicação e a interação entre os indivíduos. Além disso, como defendem Bourdieu e Passeron (1982), a escola é um espaço de lutas e violências simbólicas entre as classes sociais pela manutenção do status quo, sendo estruturada com base no habitus das classes privilegiadas e seu conjunto de capital material, cultural e social. Sendo assim, mesmo com a implementação de políticas e legislações educacionais enquanto um estímulo à equalização da educação pública no nível básico, as representações sociais de alunos, professores e comunidade escolar atravessam esse processo, produzindo discursos, significados, valores, modelos, conflitos e resistências.

A seguir, o quadro 1 apresenta como era o ensino fundamental de oito anos no Brasil até 2005 (EF8A) e como ficou o ensino fundamental de 09 anos a partir de 2006 (EF9A):

Quadro 1 - Equivalência para implantar o ensino fundamental de 09 anos

\begin{tabular}{|c|c|c|}
\hline Como era até 2005 (EF8A) & $\begin{array}{l}\text { Como passou a ser a partir de } 2006 \\
\text { (EF9A) }\end{array}$ & $\begin{array}{c}\text { Idade } \\
\text { desejável }\end{array}$ \\
\hline $1^{\circ}$ Período da pré-escola & $1^{\circ}$ Período da pré-escola & 04 anos \\
\hline $2^{\circ}$ Período da pré-escola & $2^{\circ}$ Período da pré-escola & 05 anos \\
\hline $3^{\circ}$ Período da pré-escola & $1^{\circ}$ Ano do ensino fundamental & 06 anos \\
\hline $\begin{array}{l}1^{\text {a }} \text { Série do ensino } \\
\text { fundamental }\end{array}$ & $2^{\circ}$ Ano & 07 anos \\
\hline $2^{a}$ Série & $3^{\circ}$ Ano & 08 anos \\
\hline $3^{\text {a }}$ Série & $4^{\circ}$ Ano & 09 anos \\
\hline $4^{a}$ Série & $5^{\circ}$ Ano & 10 anos \\
\hline $5^{a}$ Série & $6^{\circ}$ Ano & 11 anos \\
\hline $6^{a}$ Série & $7^{\circ}$ Ano & 12 anos \\
\hline $7^{a}$ Série & $8^{\circ}$ Ano & 13 anos \\
\hline $8^{a}$ Série & $9^{\circ}$ Ano & 14 anos \\
\hline
\end{tabular}

Fonte: Brasil - Ministério da Educação e Cultura (2006b).

A partir de 2006, o ensino fundamental de nove anos passou a ser distribuído em dois ciclos, respectivamente, $1^{\circ}$ ao $5^{\circ}$ e $6^{\circ}$ ao $9^{\circ}$. O primeiro ciclo, composto pelos cinco anos iniciais 
do ensino fundamental, passou a abranger compulsoriamente crianças de 06 a 10 anos de idade. $\mathrm{O}$ segundo ciclo, composto pelos quatro anos finais do ensino fundamental, passou a abranger adolescentes de 11 a 14 anos de idade. Assim, as crianças passaram a ingressar no $1^{\circ}$ ano do ensino fundamental aos 06 anos de idade, devendo percorrer os dois ciclos em 09 anos, concluindo o ensino fundamental aos 14 anos de idade e a etapa seguinte, o ensino médio, aos 17 anos. Além disso, com a adoção dos ciclos, a questão da reprovação também passou a ser tratada de forma diferenciada, na medida em que, no primeiro bloco pedagógico ( $1^{\circ}$ ao $3^{\circ}$ ano), a reprovação tornouse desaconselhada, exceto em situações de frequência ou em casos excepcionais (BRASIL, 2006b).

Exposto esse quadro teórico e estrutural, ao analisar as repercussões locais dessas políticas, em um caso efetivo de uma escola pública municipal de educação básica, de tamanho médio, com características similares à maior parte das escolas fundamentais brasileiras, esta pesquisa pretende contribuir com as reflexões sobre a produção social das trajetórias escolares, especialmente percorridas em contexto social desfavorável. Sabe-se que um único fator não produz isoladamente os efeitos observados, pois o fenômeno em questão é plurifatorial. Porém, na produção social da educação, a alteração significativa de um fator (como a mudança estrutural provocada por política pública) apresenta repercussões que merecem ser analisadas e avaliadas, o que constitui objeto deste trabalho.

\section{Metodologia: síntese das categorias e estratégias da pesquisa}

Foi examinado um conjunto de trajetórias escolares, percorridas em contexto social desfavorável, cujos alunos ingressaram no primeiro ano da educação básica em 2006, em uma escola pública da rede municipal, situada em um bairro popular da cidade de Juiz de Fora, Minas Gerais, Brasil, sendo a primeira coorte de estudantes, nessa escola, totalmente submetida às leis que anteciparam a idade de ingresso e ampliaram o tempo de permanência no ensino fundamental. Tal escola possui similitudes com boa parte das escolas urbanas das periferias brasileiras. Seu Índice de Desenvolvimento da Educação Básica (IDEB) variou entre 4.4 (menor índice) e 6.0 (maior índice), entre 2005 e 2015 (período em que as trajetórias foram analisadas), nos anos iniciais do ensino fundamental; e entre 3.3 (menor índice) e 5.2 (maior índice), entre 2005 e 2015, nos anos finais do ensino fundamental. Segundo o Instituto Nacional de Estudos e Pesquisas Educacionais Anísio Teixeira (INEP), em 2015, a escola contava com, aproximadamente, 506 matrículas, 25 turmas, 11 salas de aula, 46 professores, 03 turnos de funcionamento, atuando nas modalidades pré-escola, anos iniciais e finais do ensino fundamental e educação de jovens e adultos. 
A escolha desta escola se deu por suas características típicas, tendo sido selecionada para integrar a amostra de um projeto de pesquisa que teve o apoio do Observatório da Educação: parceria entre a Coordenação de Aperfeiçoamento de Pessoal de Nível Superior (Capes), o Instituto Nacional de Estudos e Pesquisas Educacionais Anísio Teixeira (INEP) e a Secretaria de Educação Continuada, Alfabetização, Diversidade e Inclusão (SECADI). Esta escola apresenta potencialidades e desafios similares à boa parte das escolas de ensino fundamental de porte médio no Brasil, situada em um bairro popular, onde é possível observar as trajetórias escolares típicas de contextos socioeconômicos desfavoráveis.

Conforme mencionado, o objetivo específico foi analisar o fluxo, isto é, aprovação, reprovação, transferência, evasão e abandono, de um conjunto de alunos entre o $1^{\circ}$ e o $9^{\circ}$ ano do ensino fundamental, de 2006 a 2014. Para tanto, foram utilizados documentos escolares oficiais, tais como diários de classe e atas de resultado final dos alunos. Esses documentos são elaborados e regulamentados pela Secretaria de Educação e repassados às escolas, devendo ser preenchidos, conferidos e assinados pelo secretário escolar, pela supervisão pedagógica, pela direção e pelos professores. Ao final de cada ano letivo, as informações são enviadas para a Secretaria de Educação, e os documentos são arquivados permanentemente na escola. A partir do diário, é possível analisar fatores sociais e demográficos, como data de nascimento e sexo, bem como registros institucionais, como aprovação, reprovação, evasão, remanejamento, transferência de turma, turno ou escola, entre outras informações relevantes, apesar de nem sempre essas informações estarem devidamente preenchidas. Diante disso, além dos diários de classe, também foram utilizadas as atas de resultado final - escrituração oficial que registra a vida escolar dos alunos a cada ano letivo, atestando, por exemplo, a matrícula, o rendimento e o aproveitamento - , buscando, com isso, situar os desfechos do maior número possível de trajetórias escolares.

O modelo de análise das trajetórias é o estudo longitudinal, o qual visa examinar as variações nas características dos mesmos elementos amostrais ao longo de um determinando período de tempo. As variáveis consideradas foram nome do aluno, ano de nascimento, sexo, condição de novato ou repetente, situação ao final de cada ano letivo. Utilizaram-se planilhas para examinar os percursos individuais e coletivos, buscando-se descrever, a cada ano, de 2006 a 2014: (1) os alunos matriculados; (2) os alunos aprovados; (3) os alunos aprovados não localizados no ano seguinte - nesses casos, os desfechos das trajetórias não estão indicados nos diários de classe e nem nas atas de resultado final e aproveitamento; (4) os alunos reprovados; (5) os alunos que reaparecem - isto é, constam como aprovados ou reprovados em determinado ano, seus nomes não aparecem no diário subsequente, reaparecendo 02 ou 03 anos depois (essa situação pode estar 
relacionada a transferências e retornos, bem como a medidas de correção de fluxo); (6) os alunos que constam como transferidos de escola; (7) os alunos que constam como inativos, os quais a escola classifica como evasão. Busca-se também realizar um exame censitário das coortes, atentando-se para as suas características gerais, como o número de alunos matriculados, quantidade de novatos e repetentes, idade e sexo, além do transcorrer das trajetórias escolares coletivas e individuais ao longo do ensino fundamental.

\section{Resultados e discussão}

No $1^{\circ}$ ano do ensino fundamental em 2006, ingressaram 53 alunos, os quais deveriam chegar ao $9^{\circ}$ ano em 2014. Entre esses alunos, 23 eram do sexo masculino e 30 eram do sexo feminino. Em relação à idade, 28 alunos nasceram em 1999, e 25 alunos nasceram em 2000, ingressando no $1^{\circ}$ ano do ensino fundamental em torno de 06 e 07 anos de idade. Ou seja, somente a metade da turma estaria na idade desejável. Ressalta-se que a Lei $\mathrm{n}^{\circ}$ 11.114/2005 tornou obrigatória a matrícula de crianças aos 06 anos de idade no ensino fundamental, e a Lei $\mathrm{n}^{\circ}$ 11.274/2006 ampliou o ensino fundamental para 09 anos de duração, com a matrícula de crianças a partir dos 06 anos de idade. Fatores individuais, como a idade de ingresso no sistema de ensino, são dados importantes para compreender a produção social do sucesso e do fracasso escolar, visto que diversas pesquisas concordam que os alunos que entram mais cedo na escola, especialmente os que fazem pré-escola, têm mais chances de obter sucesso em sua trajetória escolar (MENEZES FILHO, 2007).

Dos 53 alunos listados nos diários de classe do $1^{\circ}$ ano do ensino fundamental em 2006, todos constavam como novatos, isto é, foram matriculados no $1^{\circ}$ ano pela primeira vez. Desses 53 alunos, 49 constam nos diários do $2^{\circ}$ ano em 2007; 37 constam nos diários do $3^{\circ}$ ano em 2008; 31 constam nos diários do $4^{\circ}$ ano em 2009; 27 constam nos diários do $5^{\circ}$ ano em 2010; 23 constam nos diários do $6^{\circ}$ ano em 2011; 22 constam nos diários do $7^{\circ}$ ano em 2012; 21 constam nos diários do $8^{\circ}$ ano em 2013; 20 alunos constam nos diários do $9^{\circ}$ ano em 2014, 07 meninos e 13 meninas, o que denota forte seletividade de gênero. O gráfico 01 apresenta esses dados.

No que tange à seletividade de gênero, como observa Barbosa (2009), no Brasil, em geral, meninas obtêm notas mais altas nas avaliações educacionais em relação aos meninos, alcançando taxas mais elevadas de promoção escolar. Os fatores envolvidos nesse fenômeno perpassam dimensões culturais, sociais e psicológicas, que conformam as identidades de gênero. Barbosa (2009) chama a atenção para as representações das professoras sobre as capacidades dos alunos com base no sexo, enquanto um dos fatores que podem incidir sobre as desigualdades nas 
trajetórias escolares, identificando em sua pesquisa que meninas recebem mais avaliações positivas pelas professoras do que os meninos. Assim, muitos estudos corroboram que meninas, brancos e alunos menos pobres obtêm maior acesso e probabilidade de permanência no sistema de ensino, bem como melhores resultados educacionais (BARBOSA, 2009; MONTALVÃO, 2011).

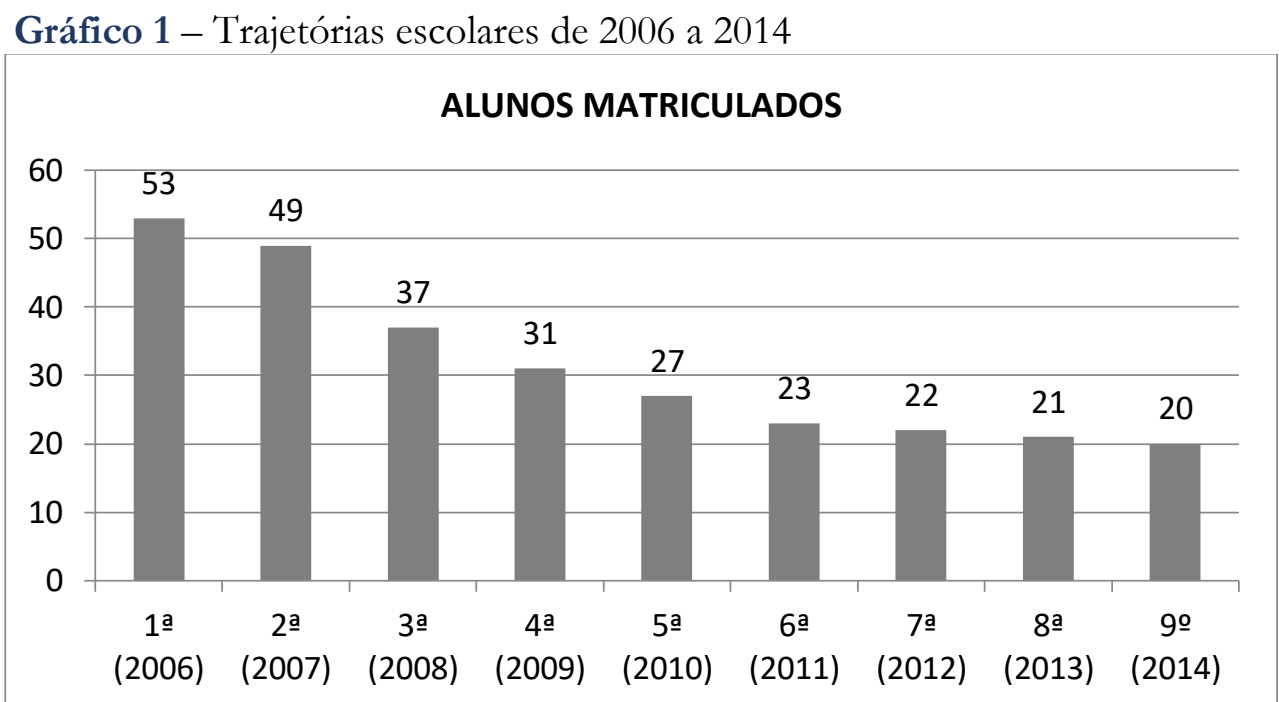

Fonte: Elaboração própria a partir dos diários de classe.

Ao detalhar esses números com base nas atas de resultado final e aproveitamento, foi possível identificar que, dos 53 alunos matriculados no $1^{\circ}$ ano do ensino fundamental em 2006, ao final do primeiro ano letivo, 01 aluno consta como inativo, 01 consta como aprovado, porém não é localizado no ano seguinte, 02 constam como transferidos, e 49 alunos constam como aprovados. Aparentemente, não houve reprovações no $1^{\circ}$ ano, pelo menos, entre aqueles que permaneceram matriculados na escola. No $2^{\circ}$ ano, em 2007, foram localizados 49 alunos. Ao final do ano letivo, 02 constam como inativos, 03 constam como transferidos, 02 constam como aprovados, porém não são localizados no ano seguinte, 05 constam como reprovados, e 37 alunos constam como aprovados. No $3^{\circ}$ ano, em 2008, foram localizados 37 alunos. Ao final do ano letivo, 01 aluno consta como transferido, 02 constam como aprovados, porém não são localizados no ano seguinte, 03 alunos constam como reprovados, e 31 alunos constam como aprovados.

No $4^{\circ}$ ano, em 2009, foram localizados 31 alunos. Ao final do ano letivo, 04 alunos constam como reprovados; e 27, aprovados. No $5^{\circ}$ ano, em 2010, foram localizados 27 alunos. Ao final do ano letivo, 04 alunos constam como reprovados; e 23, aprovados. No $6^{\circ}$ ano, em 2011, foram localizados 23 alunos. Ao final do ano letivo, 01 aluno consta como aprovado, porém não é localizado no ano seguinte, 02 alunos constam como reprovados, e 20 alunos constam como 
aprovados. No $7^{\circ}$ ano, em 2012, foram localizados 22 alunos: 20 vindos do $6^{\circ}$ ano e 02 que reaparecem no $7^{\circ}$ (entre esses 02 alunos que reaparecem, um consta como transferido no $2^{\circ}$ ano e reaparece no $7^{\circ}$ ano; o outro consta como aprovado no $2^{\circ}$ ano, porém não é localizado nos anos seguintes, sendo que o desfecho de sua trajetória não consta nas atas de resultado final e aproveitamento, mas, no $7^{\circ}$ ano, seu nome reaparece entre os alunos matriculados). Ao final do ano letivo, 02 alunos constam como reprovados; e 20, aprovados. No $8^{\circ}$ ano, em 2013, foram localizados 21 alunos: 20 vindos do $7^{\circ}$ ano e 01 aluno que reaparece no $8^{\circ}$ ano. Ao final do ano letivo, 01 aluno consta como reprovado; e 20, aprovados. No $9^{\circ}$ ano, em 2014, foram localizados 20 alunos. Ao final do ano letivo, todos constam como aprovados. É possível observar esses dados na tabela 1:

Tabela 1 - Detalhamento das trajetórias escolares do $1^{\circ}$ ao $9^{\circ}$ ano $(2006-2014)$

\begin{tabular}{|c|c|c|c|c|c|c|c|c|c|}
\hline Trajetória & $1^{\circ}$ & $2^{\circ}$ & $3^{\circ}$ & $4^{\circ}$ & $5^{\circ}$ & $6^{\circ}$ & $7^{\circ}$ & $8^{\circ}$ & $9^{\circ}$ \\
\hline Matriculados & 53 & 49 & 37 & 31 & 27 & 23 & 22 & 21 & 20 \\
\hline Aprovados & 49 & 37 & 31 & 27 & 23 & 20 & 20 & 20 & 20 \\
\hline Aprovados não localizados & 1 & 2 & 2 & 0 & 4 & 1 & 0 & 0 & 0 \\
\hline Reprovados & 0 & 5 & 3 & 4 & 0 & 2 & 2 & 1 & 0 \\
\hline Reaparecem & 0 & 0 & 0 & 0 & 0 & 0 & 2 & 1 & 0 \\
\hline Transferidos & 2 & 3 & 1 & 0 & 0 & 0 & 0 & 0 & 0 \\
\hline Inativos & 1 & 2 & 0 & 0 & 0 & 0 & 0 & 0 & 0 \\
\hline
\end{tabular}

Fonte: Elaboração própria a partir das atas de resultado final e aproveitamento.

Nota-se que somente 20 alunos chegaram com relativo êxito ao $9^{\circ}$ ano do ensino fundamental. Diz-se relativo êxito, porque não consideramos seu desempenho, ou seja, a efetiva aprendizagem desenvolvida. Por outro lado, nota-se que mais da metade da coorte sofreu algum tipo de intercorrência entre o $1^{\circ}$ e o $9^{\circ}$ ano do ensino fundamental. Esses números ajudam a compreender e explicar os péssimos índices do ensino público, bem como os baixos níveis educacionais da população brasileira como um todo. Diante disso, percebe-se que, no contexto examinado, a reprovação dos alunos parece ter sido um dos maiores obstáculos ao transcorrer das trajetórias escolares, apesar do estímulo da legislação, corroborando a produção social do fracasso escolar e a semelhança entre os destinos no que se refere à reprodução das desigualdades. A tabela 2 apresenta o estrato das trajetórias escolares em 2014, ou seja, no momento em que todos deveriam estar cursando o $9^{\circ}$ ano do ensino fundamental. 
Tabela 2 - Estrato das trajetórias escolares em 2014

\begin{tabular}{c|c|c}
\hline Ano & Etapa & Alunos localizados \\
\hline 2014 & $9^{\circ}$ Ano & 20 \\
2014 & $8^{\text {o Ano }}$ & 9 \\
2014 & $7^{\circ}$ Ano & 6 \\
2014 & $6^{\circ}$ Ano & 3 \\
2014 & EJA fase V & 1 \\
$2006-2014$ & Transferidos & 5 \\
$2006-2014$ & Inativos & 2 \\
$2006-2014$ & Aprovados não localizados & 5 \\
$2006-2014$ & Reprovados não localizados & 2 \\
\hline & Total & 53 \\
\hline
\end{tabular}

Fonte: Elaboração própria a partir das atas de resultado final e aproveitamento.

De acordo com o estrato, em 2014, dos 53 alunos que ingressaram em 2006, 20 foram localizados no $9^{\circ}$ ano do ensino fundamental regular diurno (37.7\%). Entre os demais, 19 alunos foram localizados entre o $6^{\circ}$ e o $8^{\circ}$ ano do ensino fundamental $(35.8 \%)$, ou seja, defasados. Contudo, esses 19 alunos, mesmo com defasagens, permaneceram estudando no ensino fundamental regular diurno até 2014. Apenas 01 aluno estava matriculado na Educação de Jovens e Adultos, Fase V. Verifica-se, também, que 05 alunos foram transferidos de escola no período observado; 02 alunos constam como inativos; 05 constam como aprovados em determinado ano; e 03 constam como reprovados em determinado ano, mas os desfechos dessas trajetórias não foram identificados.

Desde o final dos anos 1980, diversas pesquisas reiteraram o diagnóstico do grave problema da repetência ao longo da educação básica no Brasil. Pesquisadores como Fletcher e Ribeiro (1987), por exemplo, ressaltam que a reprovação escolar é um forte mecanismo de legitimação da distribuição desigual de bens na sociedade. Os grupos em vantagem social se empenham para garantir a reprodução de suas oportunidades, contrariando a distribuição democrática do conhecimento. Isso mantém as posições de vantagem social, bem como a estrutura da sociedade. Além disso, a repetência funciona como um mecanismo produtor da evasão, indicando a baixa qualidade da educação e um descompasso no que tange aos critérios de promoção. No entanto, as variações observadas nas taxas de repetência mostram que existe certo espaço de trabalho, em que o aumento da competência interna da escola, por si só, produz a elevação da aprovação (FLETCHER; RIBEIRO, 1987).

Em relação às reprovações, diversas pesquisas em âmbito internacional, como as de Hattie (2012), mostram que uma única reprovação compromete severamente a trajetória escolar de uma criança. Grande parte dos alunos reprovados ao longo do ensino fundamental não consegue chegar 
ao final do ensino médio, ou mesmo prolongar sua trajetória escolar até o ensino superior. Esses alunos tendem ao ensino noturno, à baixa proficiência e a poucas expectativas de prolongar suas trajetórias escolares. O problema é cumulativo, uma vez que reprovação tende a gerar mais reprovação. Diversas pesquisas indicam que a reprovação não traz nenhum benefício ao aluno ou à sociedade. A aprovação automática, progressão continuada e outros mecanismos têm se demonstrado menos negativos que a reprovação. Todavia, a cultura escolar permanece não só naturalizando como valorizando a repetência (TAVARES JR.; SIMÃO, 2016; CASTRO; TAVARES JR., 2016).

Entre os múltiplos fatores que incidem sobre a reprovação escolar, as pesquisas internacionais têm apontado as mudanças legais, ou na estrutura e no funcionamento dos sistemas de ensino, que se destacam como decisões político-sociais acerca da escolarização das gerações mais novas, sua aprendizagem e fluxo no sistema de ensino (HOUSE, 1989; FOSTER, 1993; FREY, 2005; BONVIN; BLESS; SCHUEPBACH, 2008; HATTIE, 2012). Também são salientadas as relações entre retenção, evasão e os desdobramentos das trajetórias escolares (PETERSON; DEGRACIE; AYABE, 1987; GRISSOM; SHEPARD, 1989; KACZALA, 1991; MORRIS, 1993; DAUBER; ALEXANDER; ENTEWISLE, 1993; HATTIE, 2012). Mencionamse, ainda, as atitudes de professores, gestores escolares e familiares acerca das expectativas e probabilidades de sucesso ou fracasso escolar, que são largamente conhecidas, há várias décadas (BYRNES, 1989; TOMCHIN; IMPARA, 1992). De tais estudos, emergiu a clareza acerca da diferenciação dos perfis dos retidos e evadidos (trajetórias irregulares) e os não retidos (trajetórias regulares), bem como a maior compreensão da relação entre retenção e evasão (MEISELS; LIAW, 1993; DAUBER; ALEXANDER; ENTWISLE, 1993; LIDDELL; RAE, 2001; STEARNS et al., 2007).

Diante disso, constatou-se que, dos 19 alunos defasados em 2014 (isto é, aqueles que estavam matriculados entre a Educação de Jovens e Adultos e o $8^{\circ}$ ano do ensino fundamental), 18 alunos (33\%) foram localizados na escola em 2015, um ano após o prazo mínimo em que a sua coorte deveria concluir o ensino fundamental (2006-2014). 
Tabela 3 - Localização das trajetórias escolares defasadas em 2015

\begin{tabular}{l|c|c}
\hline Ano & Etapa & Alunos Localizados \\
\hline 2015 & $9^{\circ}$ Ano & 8 \\
2015 & $8^{\circ}$ Ano & 2 \\
2015 & $7^{\circ}$ Ano & 3 \\
2015 & EJA fase VII & 3 \\
2015 & EJA fase VI & 1 \\
2015 & EJA fase V & 1 \\
2015 & Não localizado & 1 \\
\hline TOTAL & \multicolumn{2}{c}{} \\
\hline
\end{tabular}

Fonte: Elaboração própria a partir das atas de resultado final e aproveitamento

Verifica-se que, em 2015, parte dos alunos defasados progrediu, sendo que 08 chegaram ao $9^{\circ}$ ano do ensino fundamental, com apenas um ano de atraso em relação à sua coorte. Alguns alunos que estavam matriculados no ensino regular diurno em 2014 foram localizados na Educação de Jovens e Adultos, modalidade semestral, noturna, em 2015. Observa-se, assim, que, muitos alunos repetentes voltaram a repetir. Ao examinar esta coorte, considerando as informações contidas nos diários de classe e nas atas de resultado final de aproveitamento, observa-se que a reprovação é o ponto mais nevrálgico das trajetórias escolares. Do ponto de vista coletivo, a reprovação é, em grande medida, responsável pelo funil que se verifica na educação básica: muitos ingressam, mas poucos conseguem concluir da forma adequada, no tempo e na idade corretos. Do ponto de vista individual, a reprovação é, no mínimo, dispendiosa, desmotivante, não promove o aprendizado, podendo comprometer as expectativas de longevidade escolar. É inegável a quantidade de reprovação que consta nas atas. É evidente a manifestação da produção social do fracasso escolar.

Conforme destacado por Tavares Jr. e Simão (2016), a reprovação é produzida desde a matrícula do aluno; no processo de enturmação; no primeiro dia de aula. Na matrícula, já é possível observar menos esperanças em relação a grupos desfavorecidos; na enturmação, a formação de turmas piores; no primeiro dia de aula, a atenção e as expectativas já são diferenciadas, começando a operar a profecia autorrealizadora e o efeito pigmalião. A reprovação está em cada atividade, em cada exercício, em cada nota, em cada ameaça ou advertência, na própria disposição geográfica das salas. A reprovação é uma produção social: cumpre papéis sociais e políticos, estando simbolicamente associada à punição e correção. Alicerça historicamente a relação entre professores e alunos, com suas respectivas inserções e posições (contraditórias) de classe.

Entre os fatores que interferem no transcorrer das trajetórias escolares, destacam-se aqueles relacionados à escola, ou seja, às políticas e práticas do corpo escolar, leia-se, da direção, da 
coordenação pedagógica e dos professores. Neste sentido, por meio do acompanhamento longitudinal de um conjunto de trajetórias escolares ao longo do ensino fundamental, esta pesquisa observou, principalmente, a política e prática de reprovação escolar. A reprovação escolar sistemática, como prática cultural e institucional típica da tradição escolar brasileira, vem sendo criticada publicamente há décadas. No caso desta pesquisa observou-se que, do total de alunos que ingressou no $1^{\circ}$ ano do ensino fundamental em 2006, na escola em questão, somente a metade conseguiu concluir o ensino fundamental no tempo e na idade adequados, sem reprovação. A outra metade foi reprovada uma, ou mais vezes, evadiu ou foi transferida de escola. Assim, não ser reprovado ao final de cada ano letivo parece ter sido um grande desafio para os alunos no que tange ao contexto investigado.

Em relação às referidas legislações educacionais, Leis no 11.114/2005 e no 11.274/2006, ao longo do estudo longitudinal, foi possível perceber que interferiram nas trajetórias escolares ao ampliar o tempo de permanência na educação básica, antecipar a idade de ingresso e restringir a reprovação nos três primeiros anos desta etapa. Contudo, destaca-se que, mesmo a coorte que deveria ser favorecida com a ampliação do ensino fundamental também sofreu várias reprovações. Logo, a inclusão das crianças aos 06 anos de idade na escolaridade obrigatória e a ampliação do tempo de permanência que, segundo os documentos oficiais (BRASIL, 2005; BRASIL, 2006), deveriam garantir um direito constitucional, permitindo a uma parcela maior da população se beneficiar de um bem social, continuaram corroborando, no caso investigado, a desigualdade educacional e a reprodução do fracasso escolar. Assim, verificou-se um distanciamento entre a expectativa das leis e a desenvoltura das trajetórias, pelo menos no contexto investigado, ratificando a complexidade entre a formulação, implementação e os resultados das leis. Diante disso, é importante dar continuidade a esta pesquisa, examinando as coortes seguintes, tanto na escola específica tomada como exemplo quanto em todas as escolas do país, bem como os efeitos mais amplos dessas leis.

A título de comparação, a mesma metodologia foi empregada para analisar coortes anteriores à implementação das leis, para verificar como estava o fluxo dos alunos antes das mudanças. O gráfico 2 apresenta a trajetória escolar de uma coorte da mesma escola, que percorreu o ensino fundamental entre 2000 e 2007 . No que tange a essa coorte, quando os alunos estavam chegando ao final do ensino fundamental, aconteceu a implementação das Leis no 11.114/2005 e $\mathrm{n}^{\mathrm{o}}$ 11.274/2006. Diante disso, a escola fez algumas adaptações para que os estudantes matriculados anteriormente às leis não fossem prejudicados devido às mudanças. Assim, os alunos desta coorte foram da $6^{a}$ série para o $8^{\circ}$ ano, que seria o correspondente à $7^{\mathrm{a}}$ série no modelo de ensino 
fundamental de 08 anos (no qual ingressaram e deveriam concluir). Ao analisar os dados, identificase o mesmo problema da reprovação excessiva.

Gráfico 2 - Trajetórias escolares coorte 2000-2007

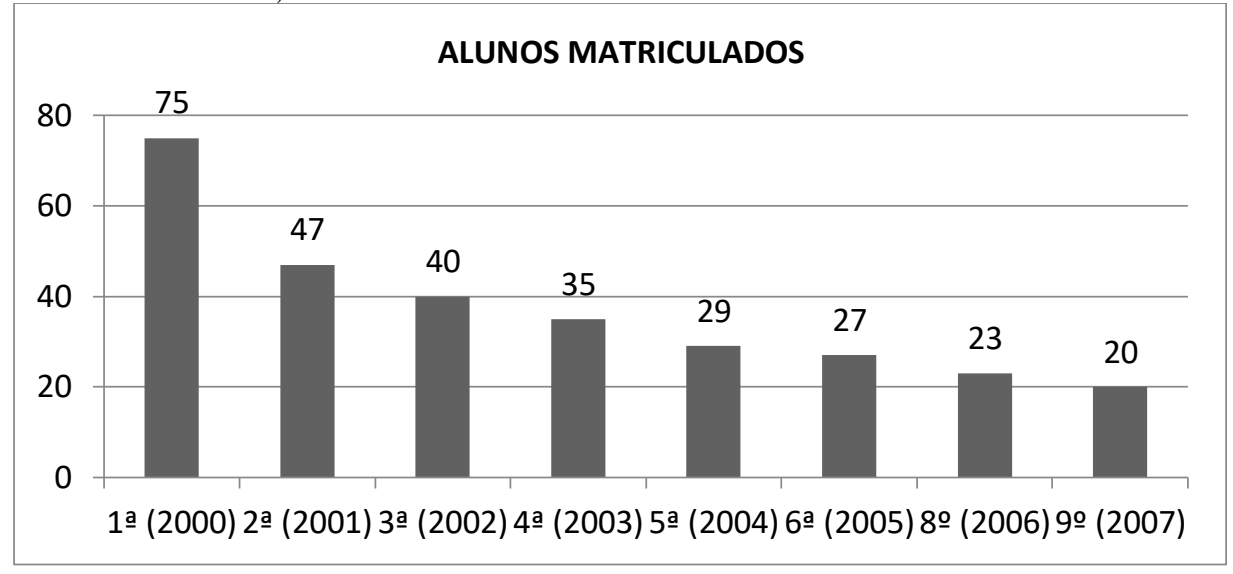

Fonte: Elaboração própria a partir dos diários de classe.

A tabela 4 apresenta o estrato das trajetórias escolares da coorte 2000-2007. Nota-se que, dos 75 alunos que compõem esta coorte, entre os alunos localizados em 2007, apenas 20 haviam concluído o ensino fundamental com relativo êxito. Porém, com exceção dos transferidos, inativos e aprovados não localizados (quem somam 27 estudantes), 28 alunos estavam em situação de defasagem escolar.

Tabela 4 - Estrato escolar da coorte 2000-2007 em 2007

\begin{tabular}{|c|c|c|}
\hline Ano & Etapa & Alunos localizados \\
\hline 2007 & $9^{\circ}$ Ano diurno regular & 20 \\
\hline 2007 & $8^{\circ}$ Ano diurno regular & 8 \\
\hline 2007 & $7^{\circ}$ Ano diurno regular & 7 \\
\hline 2007 & $6^{\circ}$ Ano noturno regular & 4 \\
\hline 2007 & $8^{\circ}$ Ano noturno regular & 1 \\
\hline 2007 & $6^{\circ}$ Ano noturno regular & 2 \\
\hline 2007 & EJA Fase IV & 1 \\
\hline $2000-2007$ & Transferidos & 7 \\
\hline $2000-2007$ & Inativos & 9 \\
\hline $2000-2007$ & Aprovados não localizados & 11 \\
\hline $2000-2007$ & Reprovados não localizados & 5 \\
\hline
\end{tabular}

Fonte: Elaboração própria a partir das atas de resultado final e aproveitamento 
Além disso, visando compreender o fluxo dos alunos antes e após a implementação das leis que anteciparam a idade de ingresso e aumentaram o tempo de permanência do ensino fundamental, também examinamos a coorte que percorreu esta etapa da educação básica de 2003 a 2010. No gráfico 3, é possível perceber que muitos ingressaram, mas poucos conseguiram concluir com sucesso o ensino fundamental. Ressalta-se que esta coorte também passou por adaptações, uma vez que as leis foram implementadas durante suas trajetórias. Assim, da $3^{\text {a }}$ série foram para o $5^{\circ}$ ano, que seria o correspondente à $4^{\mathrm{a}}$ série no modelo de ensino fundamental de 08 anos.

Gráfico 3 - Trajetórias escolares da coorte 2003-2010

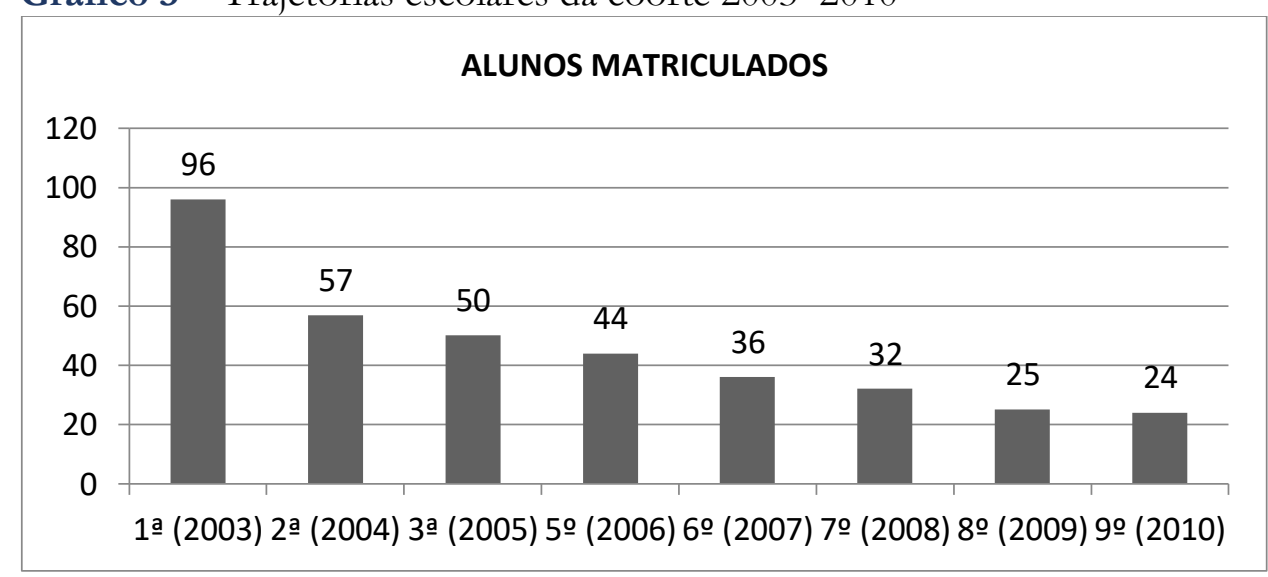

Fonte: Elaboração própria a partir das atas de resultado final e aproveitamento.

A tabela 5 apresenta o estrato da coorte 2003-2010. Com exceção dos aprovados não localizados, dos transferidos e inativos (que totalizam 22 estudantes), pelo menos 50 alunos, entre os 96 que compõem esta coorte, foram reprovados uma ou mais vezes. 
Tabela 05 - Estrato escolar da coorte 2003-2010 em 2010

\begin{tabular}{c|c|c}
\hline Ano & Etapa & Alunos localizados \\
\hline 2010 & $9^{\circ}$ Ano diurno regular & 24 \\
2010 & $8^{\text {o Ano diurno regular }}$ \\
2010 & $7^{\circ}$ Ano diurno regular & 20 \\
2010 & 6 Ano diurno regular $^{\circ}$ & 8 \\
2010 & $5^{\circ}$ Ano diurno regular & 2 \\
2010 & EJA fase VIII & 3 \\
2010 & EJA fase VII & 3 \\
2010 & EJA fase VI & 6 \\
2010 & EJA fase V & 1 \\
$2003-2010$ & Transferidos & 2 \\
$2003-2010$ & Inativos & 11 \\
$2003-2010$ & Aprovados não localizados & 9 \\
$2003-2010$ & Reprovados não localizados & 6 \\
\hline \multicolumn{2}{c}{ Total }
\end{tabular}

Fonte: Elaboração própria a partir das atas de resultado final e aproveitamento.

Diante do exposto, é importante pensar em políticas públicas e outras ações que visem à qualidade da educação básica, especialmente no que se refere à redução das taxas de reprovação escolar. Uma vez que as Leis $n^{\circ} 11.114 / 2005$ e $n^{\circ} 11.274 / 2006$ apresentam esse horizonte, tornase importante analisar suas repercussões sobre as trajetórias escolares. No caso analisado por esta pesquisa, foi possível perceber que a reprovação se manteve relativamente elevada na escola em questão, mesmo após a antecipação da idade de ingresso e aumento do tempo de permanência no ensino fundamental.

\section{Considerações finais}

Esta pesquisa buscou investigar e refletir sobre o transcorrer de um conjunto de trajetórias escolares percorridas em contexto socioeconômico desfavorável, especialmente, após a implantação das Leis Federais no 11.114/2005 e no 11.274/2006, que, respectivamente, antecipou a idade de ingresso do ensino fundamental para 06 anos de idade e ampliou a duração desta etapa de ensino de 08 para 09 anos. O contexto investigado é próximo ao observado em boa parte das escolas públicas do país, sobretudo nas redes municipais de ensino e nas escolas de periferia, onde os alunos apresentam limites ao acesso a melhores condições de escolarização e socialização, origem familiar desprivilegiada, com baixo nível socioeconômico e baixa escolaridade, aliados a restrições a oportunidades educacionais democráticas.

Nos resultados do estudo longitudinal/documental, constatou-se que, dos 53 alunos matriculados no $1^{\circ}$ ano do ensino fundamental, em 2006, no contexto investigado, somente cerca 
da metade conseguiu concluir a educação básica no tempo e idade adequados, devido, entre outros aspectos, à prática sistemática de reprovação escolar, isto é, à representação social que a reprovação preserva na cultura escolar tradicional no Brasil. Diante disso, ressalta-se que os sistemas públicos de educação básica precisam ser questionados quanto à prática sistemática de reprovação dos alunos.

Assim, observa-se que a cultura escolar no país ainda se reproduz com elementos negativos à realização educacional democrática. Percebe-se que, a cada ano letivo, os alunos precisaram vencer barreiras institucionais, cognitivas e simbólicas para permanecerem "ilesos" até o final do ciclo, ou seja, obter aprovação contínua em todas as etapas (sucesso escolar). Nesse sentido, a legislação e as políticas públicas educacionais estão falhando em garantir o direito dos indivíduos à educação de qualidade, havendo grande distanciamento entre as formulações legais e as representações sociais da comunidade escolar sobre a construção das trajetórias. Assim, fazer com que a maioria dos alunos tenha um fluxo adequado, isto é, pelo menos, sem reprovação ou evasão, mostrou-se um grande desafio para o contexto investigado, que pode ser uma pequena amostra de uma situação mais ampla.

Por fim, ressalta-se que os resultados desta pesquisa são apenas um indício do que acontece em diversos lugares do país, uma vez que esses dados convergem com resultados encontrados por outras pesquisas nacionais, tanto quantitativas quanto qualitativas. Os resultados apresentados representam uma etapa de uma agenda de pesquisa em curso que se soma e dialoga com outros trabalhos relacionados às representações sociais nas políticas e na gestão educacional no Brasil em seus complexos processos, nos diferentes sistemas de ensino e contextos sociais.

\section{Referências}

BARBOSA, M. L. O. Desigualdade e Desempenho: uma introdução à sociologia da escola brasileira. Belo Horizonte: Editora Argvmentvm, 2009.

BONVIN, P.; BLESS, G.; SCHUEPBACH, M. Grade retention: decision-making and effects on learning as well as social and emotional development. School effectiveness and school improvement, v. 19, n. 1, p. 1-19, 2008.

BOUDON, R. A desigualdade das oportunidades: a mobilidade social nas sociedades industriais. Editora Universidade de Brasília, 1981.

BOURDIEU, P.; PASSERON, J. C. A Reprodução - Elementos para uma teoria do sistema de ensino. Rio de Janeiro: Livraria Francisco Alves Ed., 1982. 
BRASIL. Lei n ${ }^{\circ} 11.114$, de 16 de maio de 2005. Torna obrigatório o início do ensino fundamental aos seis anos de idade. Brasília, DF, 2005.

BRASIL. Lei no 11.274, de 06 de fevereiro de 2006. Estabelece as diretrizes e bases da educação nacional, dispondo sobre a duração de nove anos para o ensino fundamental. Brasília, DF, 2005.

BRASIL. Ministério da Educação e Cultura. Ampliação do Ensino Fundamental para nove anos: $3^{\circ}$ relatório do programa. Brasília, DF: MEC/SEB, 2006b.

BYRNES, D. A. Attitudes of students, parents and educators toward repeating a grade. In SHEPARD, L. A.; SMITH, M. L. (Eds.). Flinking grades: research and policies on retention. London: Falmer Press, 1989.

CASTRO, V. G.; TAVARES JR., F. Jovens em Contextos Sociais Desfavoráveis e Sucesso Escolar no Ensino Médio. Educaşão e Realidade, Porto Alegre, v. 41, p. 239-258, 2016.

DAUBER, S. L.; ALEXANDER, K. L.; ENTWISLE, D. R. Characteristics of retainees and early precursors of retention in grade: Who is held back? Merrill-Palmer Quarterly, v. 39, p. 326-343, 1993.

FLETCHER, P. R.; RIBEIRO, S. C. O ensino de primeiro grau no Brasil de hoje. Em Aberto, Brasília, ano 06, n. 33, jan./mar. 1987.

FORQUIN, J. Sociologia da Educação: 10 anos de pesquisa. Petrópolis: Vozes, 1995.

FOSTER, J. E. Retaining children in grade. Childhood Education, v. 70, n. 1, p. 38-43, 1993.

FREY, N. Retention, social promotion, and academic redshirting: What do we know and need to know? Remedial and Special Education, v. 26, n. 6, p. 332-346, 2005.

GRISSOM, J. B.; SHEPARD, L. A. Repeating and dropping out of school. In SHEPARD, L.A.; SMITH, M. L. (Eds.), Fluncking grades: research and policies on retention. London: Falmer Press, 1989.

HATTIE, J. Visible learning for teachers. Routledge, New York, 2012.

HIRSCH, F. Social Limits to Growth. London: Routledge \& Kegan Paul, 1977.

HOUSE, E. R. Policy implications of retention research. In SHEPARD, L. A.; SMITH, M. L. (Eds.) Flunking grades: research and policies on retention. London: Falmer Press, 1989.

JENCKS, C. et al. Inequality: A Reassessment of the Effect of Family and Schooling in America. New York: Basic Books, 1972.

KACZALA, C. Grade retention: A longitudinal study of school correlates of rates of retention. Cleveland $\mathrm{OH}$ : Cleveland Public Schools, 1991.

KLEIN, R.; RIBEIRO, S. C. A Pedagogia da Repetência ao Longo das Décadas. Avaliação de Politicas Públicas Educacionais, Rio de Janeiro, v.3, n. 6, p. 55-62, jan./mar. 1995. 
LIDDELL, C.; RAE, G. Predicting early grade retention: A longitudinal investigation of primary school progress in a sample of rural South African children. British Journal of Educational Psychology, v. 71, n. 3, p. 413-428, 2001.

LIMA, R. C. P.; CAMPOS, P. H. F. Campo e grupo: aproximação conceitual entre Pierre Bourdieu e a teoria moscoviciana das representações sociais. Educação e Pesquisa, v. 41, n. 1, p. 6377, jan./mar. 2015.

MEISELS, S. J.; LIAW, F. Failure in grade: Do retained students catch up? The Journal of Educational Research, v. 87, n. 2, p. 69-77, 1993.

MENEZES-FILHO, N. Os Determinantes do Desempenho Escolar no Brasil. São Paulo: Instituto Futuro Brasil/ IBMEC/FEA USP, 2007.

MONTALVÃO, A. Estratificação Educacional no Brasil do Século XXI. DADOS - Revista de Ciências Sociais, Rio de Janeiro, v. 54, n. 2, p. 389-430, 2011.

MORRIS, D. R. Patterns of aggregate grade-retention rates. American Educational Research Journal, v. 30, n.3, 497-514, 1993.

MOSCOVICI, S. Representações sociais: investigações em psicologia social. Petrópolis: Vozes, 2003.

NOGUEIRA, C. M. M.; FORTES, M. F. A Importância dos Estudos sobre Trajetórias Escolares na Sociologia da Educação Contemporânea. Paidéia, Belo Horizonte, v. 3, n. 2, p. 57-74, 2004.

PETERSON, S. E.; DEGRACIE, J. S.; AYABE, C. R. A longitudinal study of the effects of the retention promotion on academic achievement. American Educational Research Journal, v. 24, n. 1, 107-118, 1987.

SAVELI, E. L. Ensino Fundamental de nove anos: bases legais de sua implantação. Práxis Educativa, Ponta Grossa, PR, v. 3, n. 1, p. 67-72, jan./jun. 2008.

STEARNS, E. et al. Staying back and dropping out: The relationship between grade retention and school dropout. Sociology of Education, v. 80, n. 3, p. 210-240, 2007.

TAVARES JR., F.; SIMÃO, T. C. O Plano Nacional de Educação e o rendimento educacional. Teoria e Cultura, Juiz de Fora, v. 11, n. 1 jan./jun. 2016.

TOMCHIN, E. M.; IMPARA, J. C. Unraveling teachers' beliefs about grade retention. American Educational Research Journal, v. 29, n. 1, 199-223, 1992. 